\title{
Improving Assessment Management Using Tools
}

\author{
Shang Gao, Jo Coldwell-Neilson, Andrzej Goscinski \\ School of Information Technology \\ Deakin University \\ Waurn Ponds, Vic. 3217 Australia
}

\begin{abstract}
This paper firstly explains the importance of assessment management, then introduces two assessment tools currently used in the School of Information Technology at Deakin University. A comparison of assignment marking was conducted after collecting test data from three sets of assignments. The importance of providing detailed marking guides and personalized comments is emphasized and future possible extension to the tools is also discussed at the end of this paper.
\end{abstract}

Keywords-assessment management; WebCT Vista; Desire2Learn; CloudDeakin; marking guide; personalized comment; Markers Assistant; On-line Grades System

\section{INTRODUCTION}

Assessment management plays very important role at all educational levels. Good aassessment management helps educators collect data about students' learning and their performance, as well as informing decisions about classroom instruction and curriculum content based on the collected data to personalize students' learning and maximise the outcomes.

The assessment process may consist of a number of tasks. First, creating assessment material, which can be essays, diagrams, drawings, programs, databases, spreadsheets and so on; then collecting the submissions after students complete the assessment; marking the submissions and recording grades before delivering feedback and results back to students. Students then review their results and if they feel they have been unfairly assessed, they can request a remark and marks adjusted accordingly.

This whole process is time consuming. Every assessor has their own customized methods and opinions of how to do the assessment. Also every assessor needs to provide accurate and meaningful evaluation feedback to students, which puts a lot of pressure on them.

To meet the assessment needs of both students and staff, the following factors should be considered [1]:

- The criteria for marking must meet the objectives of the course.

- The marking must provide a measure of the learning.

- The marking should provide effective feedback to the student.

\section{BACKGROUND AND RELATED WORKS}

There are many educational software development companies and institutions that have been providing solutions to improve student achievement. For instance,
CompassLearning Odyssey [2] provides assessment, curriculum, data management, and American state standards correlation engine. Its browser-based solution allows administrators and teachers to track student, class, school, and district data, aggregate and disaggregate the data, and produce detailed reports.

WebQuiz XP, developed by Smartlite [3], can be used to create online quizzes, tests, assessments and questionnaires. A custom explanation message can be shown if a wrong answer is chosen; users can even set a different message according to the answer given. WebQuiz XP also supports surveys or psychological tests, where questions do not have correct answers; this way, it can be used to collect data and display statistics.

Deakin University has been using WebCT Vista [4] as its primary on-line learning environment, called Deakin Studies Online (DSO) for a few years. Recently it is changed to Desire2Learn [5], called CloudDeakin. Both these learning environments are powerful teaching and learning platforms providing discussions, whiteboard, content reuse, performance reporting, on-line quizzes, easy-to-manage gradebook and assignment tools, etc. However, very few backend tools are available for assessment management in the WebCT Vista or Desire2Learn environmenst. They do not meet the many varied assessment needs of education today, such as creating a detailed marking guide, or returning students a result report with detailed comments and statistical information about the whole assignment.

For instance, in the School of Information Technology, students are usually required to submit their assignment attempts in electronic form. CloudDeakin provides dropboxs and a simple rubric editing/marking interface. But the majority of marking is still a manual process. As far as the authors are aware, many academics, especially in the mathematics discipline, simply download assignments from CloudDeakin, print them out, mark on paper and return to students. Alternatively they demand hard-copy submissions. Others may mark via the CloudDeakin provided interface directly, which is all right to provide comments, but it is hard to integrate a detailed marking guide or statistical information in the returned assessment report. Even using the rubric functionality in CloudDeakin has limitations. It is rather basic with only one grading scale accommodated across all marking criteria.

Some Computer Assisted Assessment tools support the creation of online quizzes with answersr but do not provide the functionality or flexibility that we expect and need for effective reporting of feedback to students, especially the integration 
with CloudDeakin. Colleagues in the School of Information Technology, Deakin University have developed two assessment tools, Markers Assistant (MA) [6] and On-line Grades System (OGS) [7].

The objectives of both these tools are to reduce the amount of time spent on administrative tasks associated with marking, increase the range of feedback that can be easily delivered to students, and provide an easy interface to access online submissions as well as deliver marks and feedback to students, thus allowing more time to be spent on working one-to-one with students to achieve good results.

\section{ASSESSMENT TOOLS COMPARISON}

In the following sections, we briefly introduce these two tools (Markers Assistant and On-line Grades System) and then use SIT104 Introduction to Web Development assignment marking as a case study to compare these assessment tools against the above assessment criteria. Conclusions and recommendations are also given at the end of this paper. SIT104 is a core unit in the Bachelor of Information Technology. Students generally complete this unit in the second half of their first year of study.

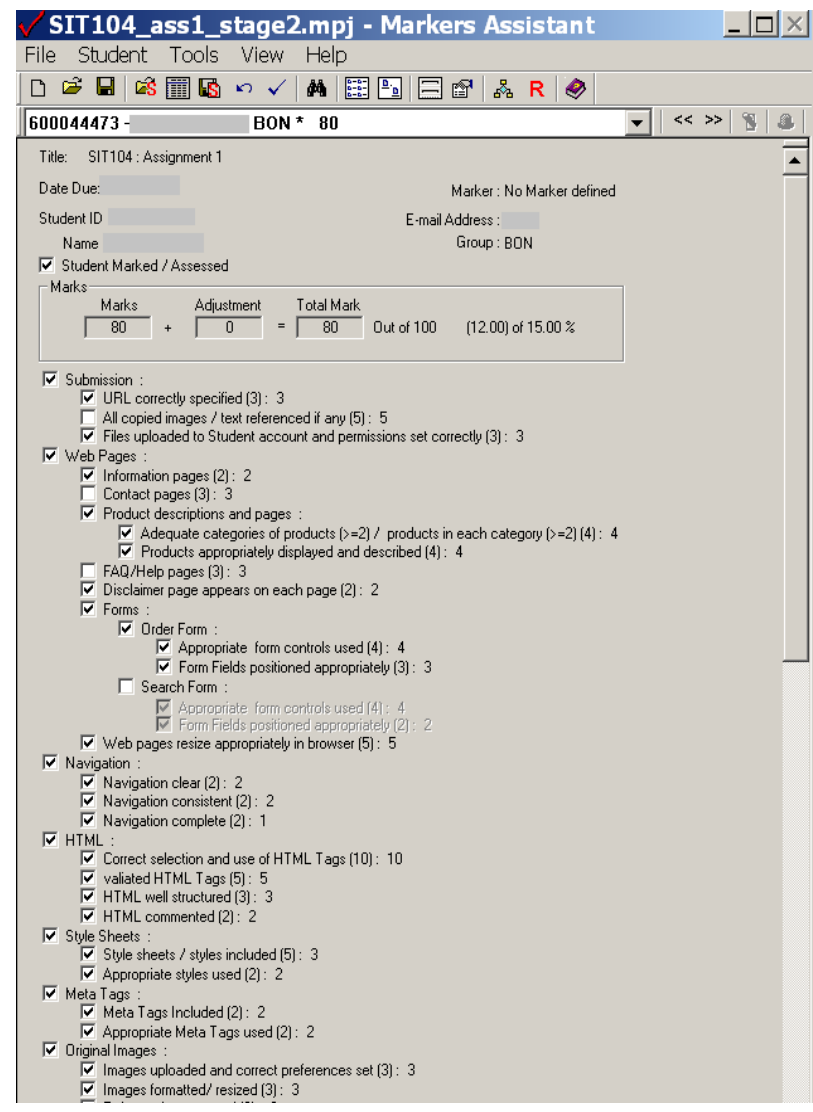

Fig. 1. Example MA marking guide

\section{A. Markers Assistant}

Markers Assistant (MA) [6] is a Windows based application developed to provide a flexible method of managing, assessing and delivering results to small and large numbers of students. It is designed to automate as many components of the marking process as possible, whilst maintaining and improving the assessment feedback to the students within a reasonable timeframe [1]. It can:

1) provide automation that retrieves student submissions and presents them via a predetermined application

Individual students are identified by information such as student number or ID and an associated email address if results are to be delivered via email. Students can be found either by identifying them in a drop down menu via there ID or email address. A predetermined application is triggered automatically based on the format of the submission.

2) provide a flexible marking guide GUI that only requires the identification of the criteria and/or assessment of an item's value

The marking guide is displayed in the form of checkboxes and is organised in a hierarchical configuration where high level criteria must be met before other items within that criteria are considered, as shown in Fig. 1.

3) automate the calculation of results within the application

Each time a checkbox is ticked the marks are adjusted accordingly. Comments can be added, edited or deleted against an individual item in the marking guide or as a general comment that relates to the submission as a whole. All comments entered are stored in a general repository and can be reused for a another student if required.

4) provide facilities to deliver student results via email

When the marking is complete, all results can be emailed to the students or exported in a file format that is recognised by WebCT or Desire2Learn.

\section{5) provide facilities to collate final marks summaries}

The result report is a text file containing the assessment criteria and the associated mark the student received for each item in the criteria. Any comments relating to the assessment are also included, as shown in Table. I. It also provides result summaries of all assessment performed, which is not possible in traditional methods of assessment. MA enables the following statistics [1]:

Marks summaries for each student:

- criterion mark; comment adjustments; total marks

Statistics for all students:

- number of students; number of students marked; number of zero marks; number of full marks; average mark; maximum mark; minimum mark

Item Statistics:

- item no; attempted; not attempted; average mark; description

Comments for all students:

- frequency

This analysis data helps students gain a better understanding of their strengths and weaknesses as well as provide them with an overview of all items within an assessment (Table. II). 
TABLE I. EXAMPLE ASSESSMENT REPORT

SIT104 -Assignment 1 Marking Guide

\begin{tabular}{|c|c|}
\hline $\begin{array}{l}\text { Legend: } \\
\text { \# - Comments have been made, refer to SPECIAL COMM } \\
\text { selecting the link }\end{array}$ & NTS by \\
\hline Submission & . \\
\hline URL correctly specified & $3 / 3$ \\
\hline All copied images / text referenced if any & $0 / 5$ \\
\hline Files uploaded and permissions set correctly & $3 / 3$ \\
\hline Web Pages & 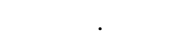 \\
\hline Information pages & $2 / 2$ \\
\hline Contact pages & $0 / 3$ \\
\hline Product descriptions and pages & . \\
\hline $\begin{array}{l}\text { Adequate categories of products }(>=2) / \text { products in } \\
\text { each category }(>=2)\end{array}$ & $4 / 4$ \\
\hline Products appropriately displayed and described & $4 / 4$ \\
\hline FAQ/Help pages & $0 / 3$ \\
\hline Disclaimer page appears on each page & $2 / 2$ \\
\hline Forms & . \\
\hline Order Form & . \\
\hline Appropriate form controls used & $4 / 4$ \\
\hline Form Fields positioned appropriately & $3 / 3$ \\
\hline Search Form & . \\
\hline Appropriate form controls used & $0 / 4$ \\
\hline Form Fields positioned appropriately & $0 / 2$ \\
\hline Web pages resize appropriately in browser & $5 / 5$ \\
\hline Navigation & . \\
\hline Navigation clear & $2 / 2$ \\
\hline Navigation consistent & $2 / 2$ \\
\hline Navigation complete & $1 / 2$ \\
\hline HTML & . \\
\hline Correct selection and use of HTML Tags & $10 / 10$ \\
\hline valiated HTML Tags & $5 / 5$ \\
\hline HTML well structured & $3 / 3$ \\
\hline HTML commented & $2 / 2$ \\
\hline Style Sheets & . \\
\hline Style sheets / styles included & $3 / 5$ \\
\hline Appropriate styles used & $2 / 2$ \\
\hline Meta Tags & . \\
\hline Meta Tags Included & $2 / 2$ \\
\hline Appropriate Meta Tags used & $2 / 2$ \\
\hline Original Images & . \\
\hline Images uploaded and correct preferences set & $3 / 3$ \\
\hline Images formatted/ resized & $3 / 3$ \\
\hline Relevant images used & $2 / 2$ \\
\hline Colors & . \\
\hline Suitable colors used & $2 / 2$ \\
\hline Consistent use of color & $2 / 2$ \\
\hline Fonts & 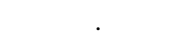 \\
\hline Font size and color suitable & $2 / 2$ \\
\hline Consistent use of Fonts & $2 / 2$ \\
\hline Sub Total & 80 \\
\hline $\begin{array}{l}\text { General Comments and Adjustments } \\
\text { 1. You should have demostrated the use of images by using } \\
\text { more than } 2\end{array}$ & 0 \\
\hline Adjustments Sub Total & 0 \\
\hline $\begin{array}{l}\text { Total Mark } \\
12.00(\text { Out of } 15.00 \%)\end{array}$ & 80 (Out of 100) \\
\hline
\end{tabular}

SPECIAL COMMENTS

Refer to the following for explanations on why you may have lost marks for individual items within the marking guide.
6) Enable all data collected to be saved and retrieved via a project file

Backup projects are automatically created in the background, as each student is marked and backup projects saved when the application is closed.

\section{TABLE II. EXAMPLE STATISTICS DATA}

\begin{tabular}{|c|c|c|c|c|}
\hline \multicolumn{5}{|c|}{\begin{tabular}{|l}
$-1-$ \\
-
\end{tabular}} \\
\hline \multicolumn{5}{|c|}{ Number of students $\quad: 210$} \\
\hline \multirow{2}{*}{\multicolumn{5}{|c|}{$\begin{array}{l}\text { Number of students marked }: 210 \\
\text { Number of students NOT marked }: 0\end{array}$}} \\
\hline & & & \\
\hline \multicolumn{4}{|c|}{ Number of zero marks $\quad: 45$} & \\
\hline \multicolumn{5}{|c|}{ Number of full marks $\quad: 32$} \\
\hline \multicolumn{5}{|c|}{ Highest mark $\quad: 100$} \\
\hline \multicolumn{5}{|c|}{ Lowest mark } \\
\hline \multicolumn{5}{|c|}{ Average mark $\quad: 68.05 / 100$} \\
\hline \multicolumn{5}{|c|}{ Average mark (no zero's) $\quad: 86.61 / 100$} \\
\hline \multicolumn{5}{|c|}{ Variance (no zero's) $\quad: 178.20$} \\
\hline \multicolumn{5}{|c|}{ Standard Deviation (no zero's) : 13.35} \\
\hline \multicolumn{5}{|c|}{ Item $\mid$ Attempted $\mid$ Not Attempted | Avg $\quad \mid$ Avg (no zero's) $\mid$ Description } \\
\hline 155 & ן & | $2.21 / 3$ & $2.82 / 3$ & ed \\
\hline $2 \mid 91$ & 119 & $|2.12 / 5|$ & $2.70 / 5$ & \\
\hline \multicolumn{5}{|c|}{ referenced if any } \\
\hline \multicolumn{5}{|c|}{\begin{tabular}{l|l|l|l|l}
$3|155| 55$ & $\mid 2.20 / 3$ & $\mid$ & $2.79 / 3$ & Files uploaded and \\
permissions set correctly
\end{tabular}} \\
\hline \multicolumn{5}{|c|}{$\begin{array}{l}\text { permissions set correctly } \\
5 \mid 153 \\
\begin{array}{l|l|l|l|l} & 57 & 1.45 / 2 & 1.84 / 2 & \text { Information pages }\end{array}\end{array}$} \\
\hline \multirow{2}{*}{\begin{tabular}{l|l}
6 & 150 \\
8 & 143
\end{tabular}} & 60 & $2.13 / 3$ & $2.72 / 3$ & Con \\
\hline & 67 & $|2.70 / 4|$ & $3.43 / 4$ & Ade \\
\hline \multicolumn{5}{|c|}{ products $(>=2) /$ products in each category $(>=2)$} \\
\hline \multicolumn{5}{|c|}{\begin{tabular}{c|c|c|c|c|}
$9|144| 66$ & $\mid 2.67 / 4$ & $3.39 / 4$ & $\mid$ Products appropriately \\
displayed and described
\end{tabular}} \\
\hline \multicolumn{5}{|c|}{ displayed and described } \\
\hline $11 \mid 156$ & 54 & $1.43 / 2$ & $1.82 / 2$ & Disclai \\
\hline \multicolumn{5}{|c|}{ on each page } \\
\hline \multicolumn{2}{|c|}{$14|122 \quad| 88$} & \multicolumn{2}{|c|}{ controls used } & $.87 / 4$ | Appropriate form \\
\hline $\begin{array}{l}15 \mid 122 \\
\text { appropriatel }\end{array}$ & 188 & | $1.70 / 3 \mid$ & $2.16 / 3$ & | Form Fields positioned \\
\hline $\begin{array}{l}17 \mid 114 \\
\text { controls use }\end{array}$ & 196 & $\mid 2.17 / 4$ & 2.7 & 76/4 | Appropriate form \\
\hline $\begin{array}{l}18 \mid 114 \\
\text { appropriatel }\end{array}$ & 196 & $|1.09 / 2|$ & $1.38 / 2$ & |Form Fields positioned \\
\hline $\begin{array}{l}19 \mid 164 \\
\text { appropriatel }\end{array}$ & $\begin{array}{l}146 \\
\text { in browser }\end{array}$ & | $3.90 / 5$ & | & $.96 / 5$ | Web pages resize \\
\hline $21 \mid 152$ & 58 & $1.42 / 2$ & $1.81 / 2$ & Navig \\
\hline $22 \mid 151$ & 59 & $1.42 / 2$ & $1.81 / 2$ & Navigati \\
\hline $23 \mid 150$ & 60 & $1.42 / 2$ & $1.81 / 2$ & Naviga \\
\hline $25 \mid 165$ & 45 & | 7.84/10 & $9.98 /$ & $10 \mid \mathrm{Col}$ \\
\hline use of $\mathrm{H}$ & Tags & & & \\
\hline $26 \mid 77$ & 133 & $\mid 1.83 / 5$ & $2.33 / 5$ & val \\
\hline $27 \mid 165$ & 45 & $2.36 / 3$ & $3.00 / 3$ & HT \\
\hline $28 \mid 161$ & 49 & $1.53 / 2$ & $1.95 / 2$ & HTML co \\
\hline $\begin{array}{l}30 \mid 157 \\
\text { included }\end{array}$ & $\mid 53$ & | 3.69/5 | & 4.65 & 9/5 | Style sheets / styles \\
\hline $31 \mid 159$ & 51 & $1.51 / 2$ & $1.93 / 2$ & sed \\
\hline $33 \mid 163$ & 47 & $1.55 / 2$ & $1.98 / 2$ & Met: \\
\hline $\begin{array}{l}34 \mid 161 \\
\text { used }\end{array}$ & 49 & $1.53 / 2$ & $1.95 / 2$ & | Appropriate Meta Tags \\
\hline $\begin{array}{l}36 \mid 156 \\
\text { correct pref }\end{array}$ & $\begin{array}{l}\mid 54 \\
\text { rences set }\end{array}$ & $|2.22 / 3|$ & $2.83 /$ & /3 Images uploaded and \\
\hline $\begin{array}{l}37 \mid 158 \\
\text { resized }\end{array}$ & $\mid 52$ & | $2.26 / 3$ & 2.8 & 87/3 | Images formatted/ \\
\hline $38 \mid 156$ & 54 & $1.49 / 2$ & $1.89 / 2$ & \\
\hline & 47 & $1.55 / 2$ & $1.98 / 2$ & \\
\hline $41 \mid 162$ & 48 & $1.54 / 2$ & $1.96 / 2$ & Consistent use of color \\
\hline
\end{tabular}




\begin{tabular}{|l|l|l|r|r|}
\hline $\begin{array}{c}43 \mid 162 \\
\text { suitable }\end{array}$ & $\mid 48$ & $\mid 1.54 / 2$ & $1.96 / 2$ & $\mid$ Font size and color \\
$44 \mid 163$ & $\mid 47$ & $\mid 1.55 / 2$ & $1.98 / 2$ & $\mid$ Consistent use of Fonts \\
\hline
\end{tabular}

\section{B. On-line Grades System}

On-line Grades System (OGS) [7] is a Web based application developed to provide an easy way to access hyperlink-based assignments, assessing them and delivering the results within a browser.

It is designed to automate hyperlink access, to mark assignments via a GUI and to send feedback to students purely online. It can:

1) provide automation that retrieves student submitted hyperlinks and presents them in a browser.

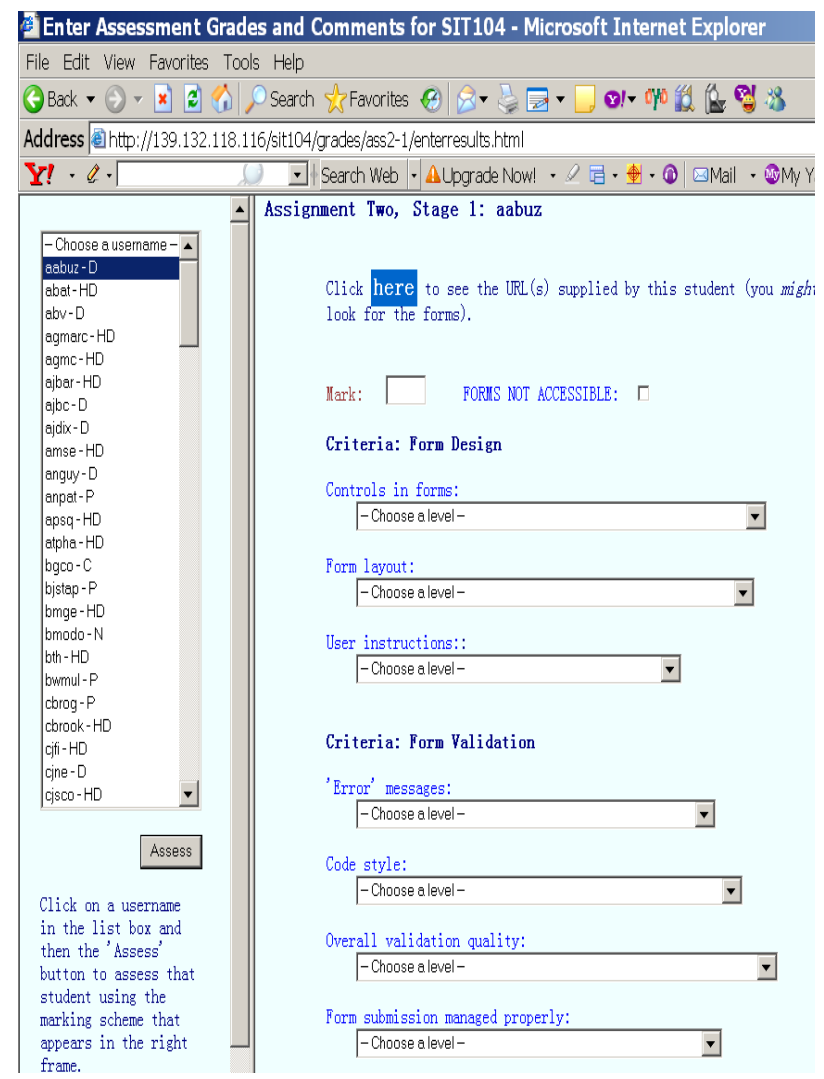

Fig. 2. Example OGS marking guide

Individual students are identified by an associated email address. Students can be selected from an email address selection menu.

2) provide an easy to use marking GUI that only requires the identification of the criterion and assessment value for an item after loading a HTML based marking guide.

Detailed marking guide items are displayed in the form of dropdown lists, as shown in Fig. 2.

3) automate the calculation of results within the application
Each time a dropdown list item is chosen, the mark is adjusted accordingly. Comments can be added, edited or deleted at the bottom of the marking guide page.

4) provide a seperate interface to deliver student results online

When the marking is completed, all results can be viewed via a "lookup result" interface by typing the student ID and email address. The result report is a file stored in the underlying database containing the assessment criteria and the associated mark that the student receives for each item in the criteria. All the comments relating to the assessment are also included, as shown in Fig. 3.

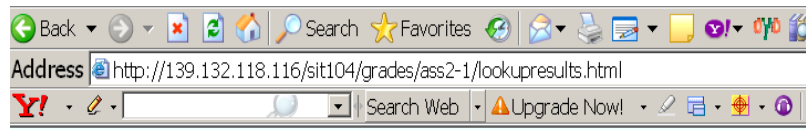

P1ease enter your ID Number and Deakin username:

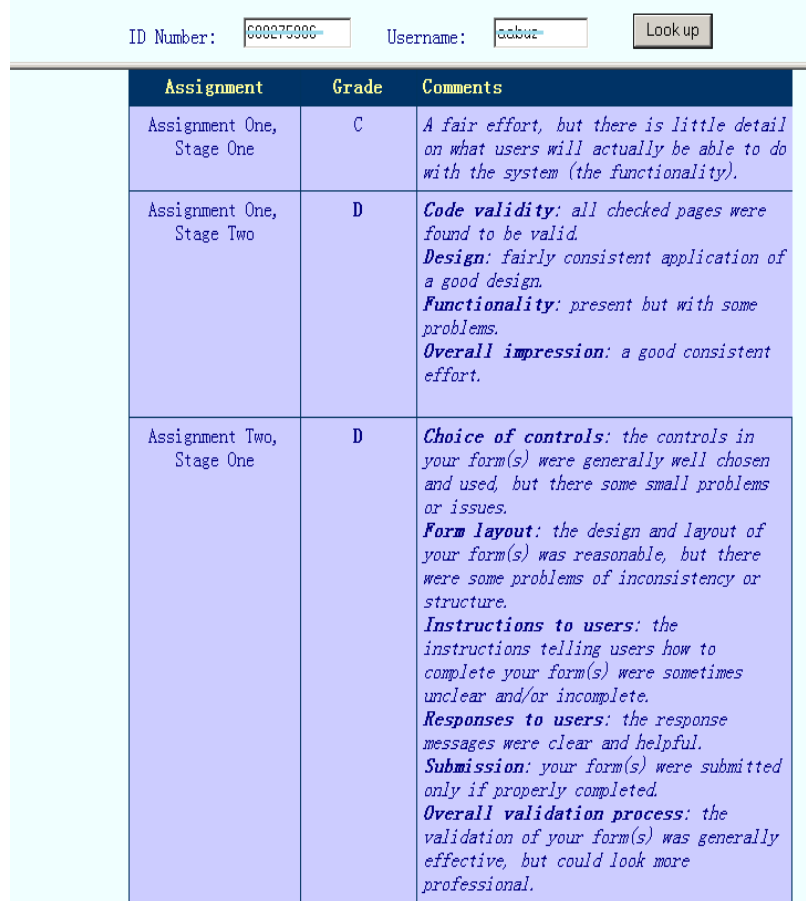

Fig. 3. Example OGS assessment report

5) enable all data collected to be saved and retrieved via a database

Backup has to be done manually to ensure the marking and comments are saved in the database.

\section{COMPARISON AND CONCLUSION}

To compare these two tools, data was collected relating to the first and second assignments in the unit SIT104 Introduction to Web Development during trimester 2, 2012. The first two stages of the second assignment were included in the comparison. The unit SIT104 is delivered to students on three campuses, on-campus at Geelong (in regional Victoria), on-campus at Burwood (suburban campus in Melbourne) and off-campus (ie distance education). 


\section{A. Comparison}

For assignment 1, both the MA and OGS were used to mark submissions made by the Geelong on- and off-campus students. The MA is used to provide just detailed comments to students but not the mark; the actual marking that was distributed to students was completed using the OGS.

For assignment 2 stage 1, the MA and OGS were both used for marking all submissions. To maintain consistency, only the OGS results were released to students, together with the comments created in MA.

For assignment 2 stage 2, the OGS is used for marking all student submissions. Comments were made as informative as possible on each submission in OGS.

Student feedback was collected via email query, in-class and after-class discussion.

By comparing these three different marking methods and feedback from students, the following similarities and differences are found:

- Similarities:

a) Both of the assessment tools support an easy-to-use interface with file loading automation;

b) Both of the assessment tools automate the calculation of results within the application;

c) Both of the assessment tools support data backup.

- Differences:

a) MA results are sent out via email; OGS results can be viewed online;

b) MA backups results in .txt file; OGS stores all the data in a database;

c) $M A$ receives positive feedback on detailed marking criteria and personalised comments on each item;

d) $M A$ receives positive feedback on providing results summaries and statistics information;

e) OGS's marking guide is considered somewhat "vague" and needs to be refined;

f) Well commented OGS marking results receive near "zero" marking complaints;

g) Although MA's comments can be reused, there is a low limit on the size of the comment editing field, whereas OGS provides enough text area to accommodate long comments;

h) OGS does not require additional training once the assessment environment is setup; MA requires additional training because of the availability of more powerful functionality.

\section{B. Conclusion}

The marking guide identifies the expectations of the assessment and the marks provide a measure of the student's success in meeting the expectations. In addition to the marking guide, it would be better to provide information for each marking item which explains what the expectation of each item is.
It was found that when students are given a correct answer they would not only identity where they went wrong for themselves but also discover what is required or is correct. From this point of view, no matter what kind of assessment tools we use, providing detailed and informative comments also help students improve their learning outcomes.

According to a recommendation of the University's Teaching and Learning Committee [8], feedback on assignments to students should:

- Be clearly linked to each published assessment criterion

- Assist learning, reward achievement, provide encouragement, explain results and enable students to improve their performance

The evidence provided above also suggests that a well written marking guide and informative comments does provide meaningful feedback to students.

\section{FUTURE WORK}

The above two assessment tools remove much of the complication from assessment by automating many of the tedious tasks, which allows assessors to focus on the assessment itself rather than the associated administrative processes.

Also the marking guides created using the tools are reusable and editable for future assessments.

Other features that will further improve the supporting environments and functionality of the two tools include:

For MA:

- Extend the system to allow annotated attachments to the results

- Provide database connectivity

For OGS

- Provide facilities to create and edit a marking guide within the application

- Add statistical output.

By combining the positive features of the two tools, a comprehensive, easy to use marking tool can be developed that not only minimises the tedious tasks of marking from an academic's perspective, but also provides students with comprehensive, detailed feedback that will encourage them to learn from their mistakes.

\section{REFERENCES}

[1] J. Wells, W. Zhou, N. Paul, C. Brian, F. Joseph (2003), “Assessment management using software, Advances in web-based learning", International confererence on web-based learning (ICW1 2003), 18-20 August 2003, Melbourne , AUSTRALIE 20031973, vol. 2783, pp. 411-422, ISBN 3-540-40772-3.

[2] CompassLearning Odyssey, Compass Learning Website, available < http://www.compasslearning.com/assessment />, accessed 24/05/2013.

[3] Smartlite (2005), Smartlite software Website, available < http://eng.smartlite.it/en2/products/webquiz/index.asp >, accessed 24/05/2013. 
[4] webCT Vista, Blackboard Website, available < http://www.blackboard.com/About-Bb/Overview.aspx> , accessed 25/05/2013.

[5] Desire2Learn, Desire2Learn website, available $<$ http://www.desire2learn.com/>, accessed 31/05/2013.

[6] Markers Assistant, Surreal Website, available <http://www.surreal.com.au>, accessed 25/05/2013.
[7] On-line Grades System (OGS), Deakin University Website, available < http://139.132.118.116/sit104/grades/ass2-1/enterresults.html>, accessed 25/01/2013.

[8] Deakin University, Appropriate levels and timing of feedback to students on assignments - operational plan target 1.3.6, Teaching and Learning Committee, Agenda paper 9.1, AB05/07/124, unpublished. 